\title{
Recent patent applications in neural engineering
}

\begin{tabular}{ll} 
Patent number & Description \\
\hline US8862219B2 & $\begin{array}{l}\text { A method of and system for creating a user profile } \\
\text { for use in a brain computer interface }(\mathrm{BCI}) \text {, and a } \\
\text { method of and system for creating a } \mathrm{BCl} \text { for a user } \\
\text { for an application. }\end{array}$
\end{tabular}

US8849727B2

US20140249396A1

An implantable electrode of electrode array designed for brain recording and/or stimulation.

US20140228701A1 A method involving determining one or more features of brain neural signals using a $\mathrm{BCl}$. Anonymized neural signals are generated using the $\mathrm{BCl}$ anonymizer of the $\mathrm{BCl}$ by filtering one or more features to remove private information. One or more application commands for the $\mathrm{BCl}$-enabled application are generated from the anonymized neural signals using the $\mathrm{BCl}$. One or more application commands are sent from the $\mathrm{BCl}$.

US20130144145A1 Implantable neural tissue reporting probes and methods of manufacturing and implanting the same.

US20130096453A1 $\mathrm{BCl}$ devices and methods for precise control of an object to be controlled. The device has a brain wave information processing unit receiving converted brain wave information including object motion information, and extracting object control information including the object motion information from the converted brain wave information.

US20130072775A1 Methods and devices related to electrophysiological measurement over a complex-shaped biological surface, such as the brain. Specially configured devices are conformable and provide the ability to measure complex spatiotemporal waveforms over relatively large areas of the brain, including in areas requiring high device bendability such as between brain hemispheres.

US20120296569A1 A method involving receiving neurophysiological data, and identifying features and relations among features in the neurophysiological data.

US8090674B2
Systems for recording of neuronal signals, and more particularly to an integrated system for multichannel neuronal recording with spike/local field potential (LFP) separation, integrated A/D conversion and threshold detection. A band splitter separates the analog signals into low-frequency LFP and high-frequency spike data, which are band limited by programmable cut-off low-pass filter. Several analog/digital converts convert the analog signals into bits.

\section{Assignee}

Koninklijke Philips

(Eindhoven, the

Netherlands),

Garcia Molina GN,

Bruekers AAML,

Damstra MC, Weda J

Lu S, Agency

for Science

Technology and

Research (Connexis,

Zhang $\mathrm{H}$

Shacham-Diamand $\mathrm{Y}$,

Ramot at Tel Aviv

University Ltd.

(Tel Aviv, Israel),

Mintz M, Taub A

University of

Washington Center

for Commercialization

(Seattle)
Singapore), Guan C,

Lu S, Guan C,

$5 / 26 / 2008$

9/30/2014

Zhang $\mathrm{H}$

Shacham-Diamand $Y$,

Mintz M, Taub A

$8 / 4 / 2011$

9/4/2014

Chizeck HJ, Bonaci T

2/11/2013

$8 / 14 / 2014$

University of

Meng $\mathrm{E}$

$12 / 5 / 201$

6/6/2013

Southern California

(Los Angeles)

Seoul National

University R\&DB

Kim JS, Chung CK,

10/12/2011

$4 / 18 / 2013$

Foundation (Seoul),

Kim JS, Chung CK,

Yeom HG

Rogers J, Kim DH, Litt B, Viventi J

Rogers J, Kim DH,

$6 / 3 / 2011$ Litt B, Viventi J
Elminda Ltd. (Herzlia, Shaha G, Reches A, Israel)

Technion Research and Development Foundation Ltd. (Haifa, Israel)
Geva AB, Pinchuk N,

Ben-Bassat G, Kanter A,

Shani-Hershkovich R,

Gadot R, Stern Y

Ginosar R, Perelman $Y$
$1 / 18 / 2010$

$11 / 22 / 2012$

Source: Thomson Scientific Search Service. The status of each application is slightly different from country to country. For further details, contact Thomson Reuters (Search Service), 1925 Ballenger
Avenue, Suite 400, Alexandria, VA 22314 , USA. Tel: 1 (800) $337-9368$ (http://thomsonreuters.com/).

Avenue, Suite 400, Alexandria, VA 22314, USA. Tel: 1 (800) 337-9368 (http://thomsonreuters.com/). 